\title{
URBANIZATION AND DYNAMICS OF ECONOMIC GROWTH (THE CASE OF NUTS 2 REGIONS OF EUROPEAN UNION)
}

\author{
Michaela Staníčková \\ Lukáš Melecký \\ VŠB-Technical University of Ostrava, Czech Republic
}

Regional development policies based on local potential triggers a shift in the economic structure of territories. Exogenous and endogenous factors determine potential of regional development and it is necessary to use different indicators and methods to its evaluation. For the paper purpose, it is required to define metropolitan and peripheral functions as well as urban areas in the form of geographic models, depicting their spatial distribution in the European Union (EU). Nowadays, regions are increasingly becoming the drivers of the economy. All regions possess development opportunities - however, use these options enough, and hence the competitiveness of regions must be efficient enough. The paper focuses on dividing the EU NUTS 2 regions based on geographic models of the European economy into efficient and inefficient ones and identifying an optimal benchmark for inefficient regions as a strategy for enhancing their economic structure to measure regional efforts and progress.

Keywords: competitiveness, data envelopment analysis, efficiency, European Union, geographic model, globalization, index, metropolitan region, NUTS 2 region, regionalization, urbanization world economy

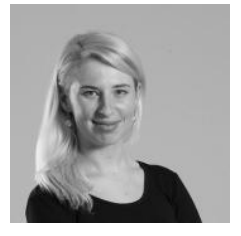

Michaela Staníčková

is an Assistant Professor of economic science (since 2014) at the VŠB-Technical University of Ostrava, Faculty of Economics, and Department of European Integration in the Czech Republic. Her scientific interests are the EU competitiveness (in line with efficiency and effectiveness of public spending and the EU resilience to economic shocks), and implementation of the EU structural aid through projects co-financed by the EU funds. She is (or was) member of several international or national research projects. Since 2010, she published seven papers in scientific books, 18 articles in professional journals, many papers in conference proceedings, of which 26 records registered in the Thomson Reuters database and 10 records in Scopus database.

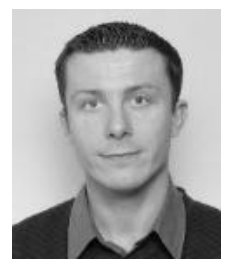

\section{Lukáš Melecký}

is an Assistant Professor of economic science (since 2004) at the VŠB-Technical University of Ostrava, Faculty of Economics, and Department of European Integration in the Czech Republic; and head of Department of European Integration (since 2016). His scientific interests are aspects of regional disparities, cohesion and competitiveness of EU Member States and regions, implementation of the EU Cohesion policy and programming of EU structural aid in the regional development of the Czech Republic through preparation of projects proposals co-financed by the European funds. He is (or was) member of several international or national research, pedagogical and development projects. He is co-author of one monograph, he published seven papers in scientific books, 21 articles in professional journals, many papers in conference proceedings, of which 24 records registered in the Thomson Reuters database and 4 records in Scopus database. 


\section{URBANIZATION AND DYNAMICS OF ECONOMIC GROWTH}

\section{Introduction: theoretical basics of regional competitiveness evaluation}

In the last few years, the topic about regional competitiveness stands in the front of economic interest. Current economic fundamentals are threatened by shifting of production activities to places with better conditions. In the global economy, regions are increasingly becoming the drivers of the economy. Successful implementation of economic policies at the regional level requires information on the specific factors that determine the pattern of regional growth and competitiveness.

Nowadays competitiveness is one of the fundamental criteria for evaluating performance and reflects the success in broader comparison. Territories need highly performing units to meet their goals, to deliver the products and services they specialised in, and finally to achieve competitive advantage. Comparative analysis of performance in public sector is the starting point for studying the role of its two dimensions - efficiency and effectiveness, regarding economic governance of resources utilisation by public management for achieving medium/long-term objectives of economic recovery and sustainable development of economies. Increasing productivity is generally considered to be the only sustainable way of improving living standards in the long term period, and not only at microeconomic level as well as at macroeconomic level (Pakšiová, 2017). Concept of competitiveness is linked with performance; competitiveness measures "how a nation manages the totality of its resources and competencies to increase the prosperity of its people' (Porter, 2003), see Fig. 1.

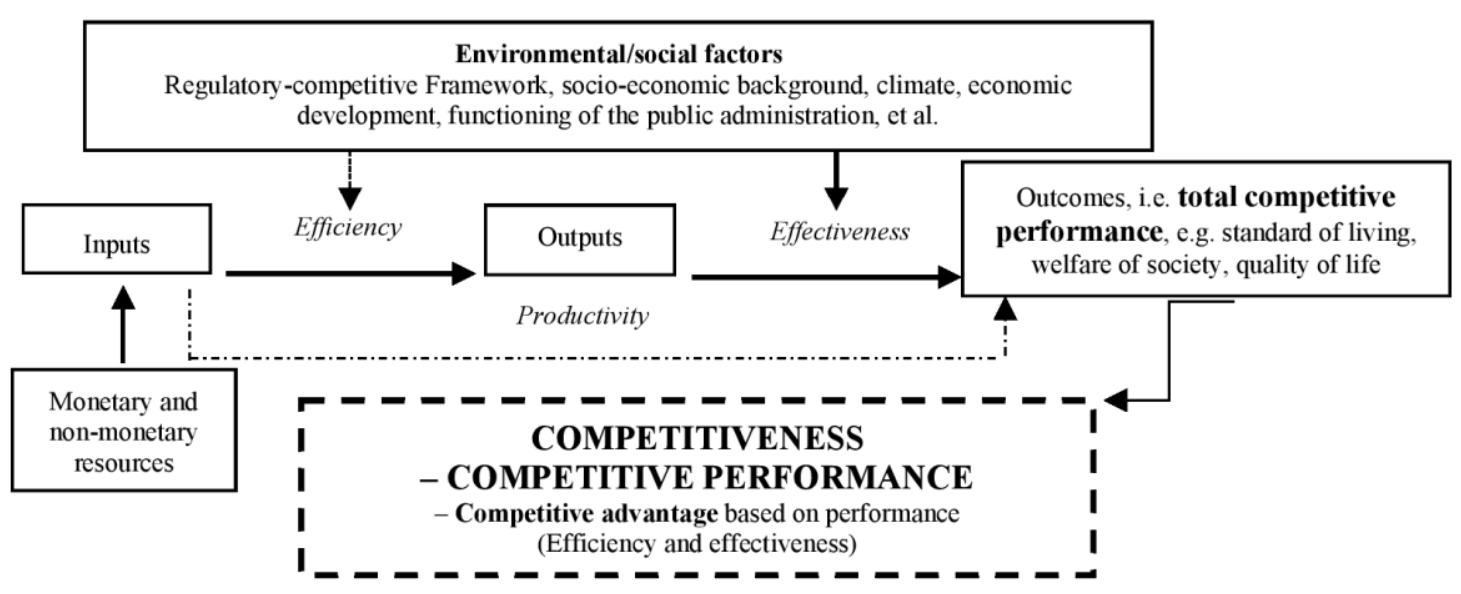

Figure 1 - The Relationship between Efficiency and Effectiveness

(Source: own elaboration, 2019)

Using interconnections between competitiveness - productivity and RCI's meaning of competitiveness, it's possible to decide on a quantitative method to competitiveness measuring and evaluating.

A suitable method to productivity measurement can be considered a DEA approach because it does not assess only one factor, but a set of different factors that determine the level of productivity. Variables employed in the empirical analysis are chosen based on RCI's approach to competitiveness, and RCI has many dimensions. Treating some these dimensions as inputs and outputs in a production process, the paper exploits the notion of productive 
efficiency to extract information for policymakers, which cannot be otherwise obtained from conventional studies on competitiveness or indices approach alone.

Using thus DEA approach is also suitable with respect to link to the main aim of competitiveness; it is the competitiveness of economies - the level of productivity of continents, nations, subnational regions, and even cities - that determines how well they translate openness to trade and investment into opportunities for their firms, farms, and people and into overall transformation process in the form of input-output relations. Total competitive performance does not depend primarily on efficiency, but effectiveness of the overall economic processes (as shown in Fig. 1).

Efficiency is given by the ratio of inputs and outputs. Effectiveness implies the relationship between outputs and outcomes. In this sense, the distinction between output and outcome must be made. The outcome is often linked to welfare or growth objectives and therefore may be influenced by multiple factors. Effectiveness is thus more challenging to assess than efficiency since outcome is influenced by political choice (Mihaiu et al., 2010).

In this paper, we evaluate the efficiency of strength economic axis, resp. how powerful in economic growth and efficient in competitiveness are these core areas (based on following approaches: Pentagon, Blue Banana, Sunbelt, Yellow Banana, RCI2013/2016) which are crucial for the European economy according to the theory of geographic models. Several quantitative approaches to measuring economic growth, convergence and competitiveness of European territorial units exist.

Corrado et al. (2005) develop an approach that identifies both the number and the composition of convergence clubs using pair-wise stationarity tests on time-series data, but for a variety of conditioning variables. Using these variables, Corrado et al. (2005) test for regional "convergence-clusters" across the EU regions against several hypothetical, a priori determined clusters.

However, an application of this methodology across all the regions of the $27 \mathrm{EU}$ countries is entirely feasible, since it requires an extensive time-series data for variables such as R\&D labour and so forth; a requirement that it is difficult to fulfil, especially for the "new" member states. Using cross-section methodologies, on the other hand, can overcome the problem of small data sets for particular conditional variables (Alexiadis, 2013). Durlauf et al. (2005) apply a "tree-regression" method using cross-section data sets, and a conditional convergence equation is estimated excluding those economies that do not fulfil certain criteria, defined ex-ante. Application of such a methodology seems to be biased in identifying a predetermined convergence club.

Moreover, applying a "tree-regression" method in a regional context fails to take into account the spatial dimension of the growth and convergence process (Fischer \& Stirböck, 2006). Another approach in territorial analysis is based on Multicriteria Decision Making Methods (MCDM), e.g. Poledníková (2014) uses MCDM for comparison of regions' ranking in the case of Visegrad Four. Staníčková \& Melecký $(2011,2016)$ or Nevima \& Ramík, (2010) use DEA method for measuring efficiency level of transform inputs into outputs (in relation to competitiveness) of the EU countries and especially regions.

Efficiency analysis starts from building a database based on RCI approach (Annoni \& Kozovska, 2010, Annoni \& Dijkstra, 2013, Annoni et al., 2017). RCI is computed as a weighted score of three sub-indices, i.e. SubInd1: RCI-Basic, SubInd2: RCI-Efficiency and SubInd3: RCI-Innovation, and covers thus a wide range of issues related to competitiveness. RCI is based on pillars describing both inputs and outputs of territorial competitiveness, 


\section{URBANIZATION AND DYNAMICS OF ECONOMIC GROWTH}

grouped into three sets describing basic, efficiency and innovative factors of competitiveness, i.e. mentioned sub-indices. Inputs and outputs describe driving forces of competitiveness, and direct or indirect outcomes of a competitive economy, see Fig. 2.

RCI seems to be convenient to using DEA, concerning its division on input and output nature of the database.

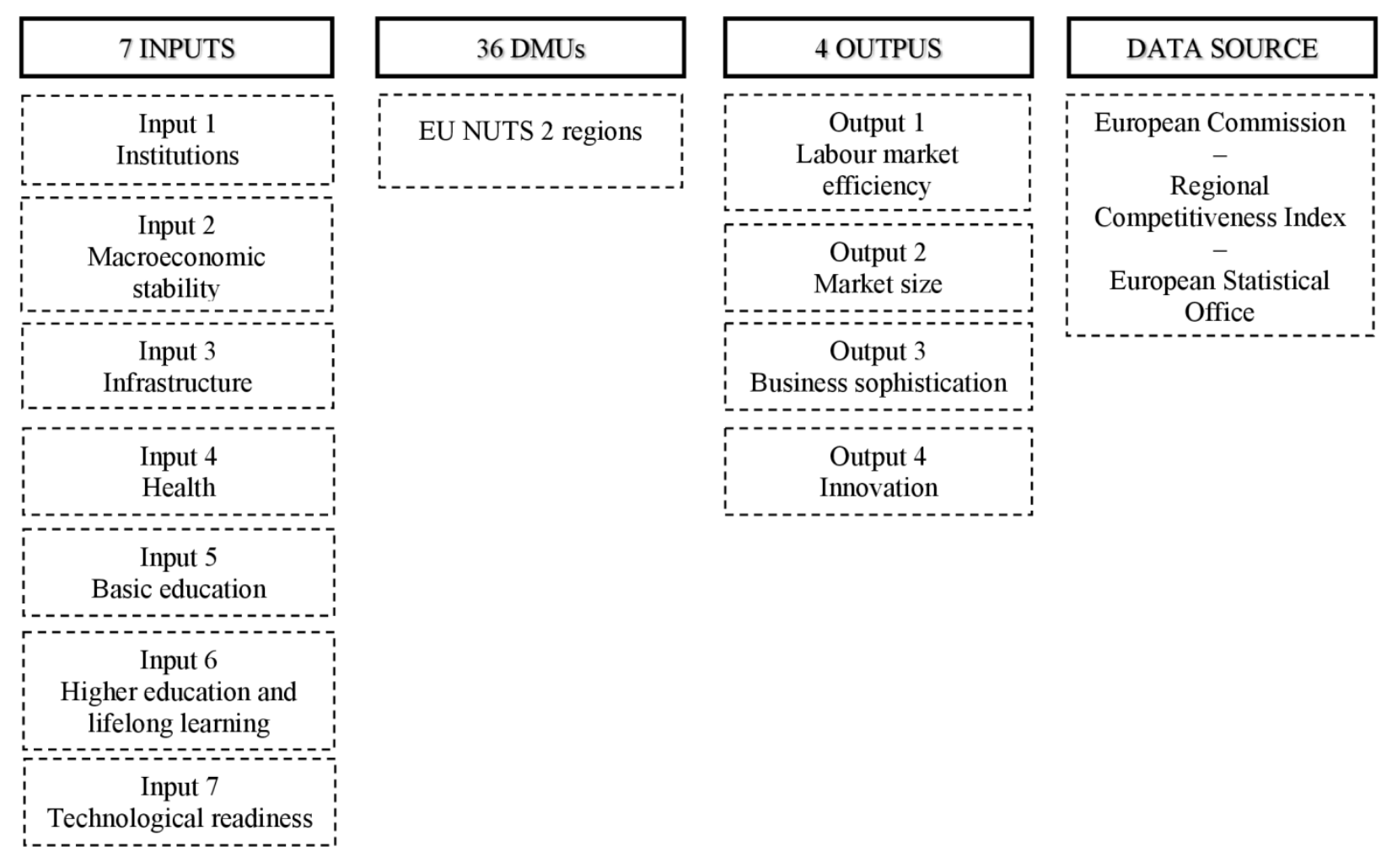

Figure 2 - Input and Output Scheme of Regional Efficiency Evaluation

(Source: own elaboration, 2019)

\section{DEA Methodology}

Performance management is one of the primary sources of sustainable organisational efficiency, and a systematic understanding of the factors that affect productivity is fundamental. Measurement and analysis of efficiency change present a controversial topic enjoying a great deal of interest among researchers and practitioners. Statistical evidence to help policymakers understand the routes to performance growth, especially those which can be influenced by government, can help lead to better policy.

The primary problem in creating an evaluation of any system is establishing clear performance standards and priorities at the beginning of the performance cycle. The early research work on this problem focused on separate measures of productivity, and there was a failure to combine the measurements of multiple inputs into any adequate measure of efficiency. 
These inadequate approaches included forming the average productivity for a single input (ignoring all the other inputs) and constructing an efficiency index in which a weighted average of the inputs is compared with the outputs.

Responding to these inadequacies of separate indices of labour productivity, capital productivity and so on, Farrell (1957) proposed an activity analysis approach that could deal more adequately with the problem. Farrell had already investigated the question of how to measure efficiency and highlighted its relevance for economic policymakers. Since that time, the techniques to measure efficiency have improved, and investigations of efficiency have become more frequent. Twenty years after Farrell's model, and building on those ideas, Charnes et al. (1978), responding to the need for adequate procedures to assess the relative efficiencies of multi-input/multi-output production units, introduced a powerful methodology that has been titled DEA.

There are several methods for measuring efficiency, besides the basic DEA models, certain modifications exist. DEA approach is based on the simple model of Farrell for measuring the efficiency of units with one input and one output initially expanded in 1978 by Charnes, Cooper, and Rhodes (CCR model) assuming constant returns to scale (CRS), and later modified in 1984 by Banker, Charnes, and Cooper, in the form of BCC model assuming variable returns to scale (VRS) (Banker et al., 1984).

DEA approach also includes advanced additive models, such as Slacks-Based Model (SBM) introduced by Tone, and Free Disposal Hull (FDH) and Free Replicability Hull (FRH) models, which were first formulated by Deprins, Simar, and Tulkens.

DEA is an approach for providing a relative efficiency assessment and evaluating the performance of a set of peer entities called decision-making units (DMUs), which convert multiple inputs into multiple outputs. DEA is thus a multi-criteria decision-making method for evaluating the efficiency of a group of DMUs.

The definition of a DMU is generic and flexible. DEA aims to examine DMU into two categories - efficient and inefficient. DEA is convenient to determine the efficiency of DMU, which are mutually comparable - using the same inputs, producing the same outputs, but their efficiencies are different. Efficient DMUs have equivalent efficiency score, but they don't have necessarily the same performance. DMU is efficient if the observed data correspond to testing DMU on the imaginary efficient frontier. All other DMUs are inefficient. The best-practice units are used as a reference for the evaluation of the other group units.

The first step in efficiency analysis is Returns to Scale (RTS) estimation. Why is it necessary to decide RTS orientation? Various types of DEA models can be used, depending upon the problem at hand. Used DEA model can be distinguished by scale and orientation of the model. If one cannot assume that economies of scale do not change, then a variable returns to scale (VRS) type of DEA model, is an appropriate choice (as opposed to constant returns to scale (CRS) model).

If to achieve better efficiency, governments' priorities are to adjust their outputs (before inputs), then an output-oriented (OO) DEA model, rather than an input-oriented (IO) model, is appropriate. There are also no IO or OO models, but the distance from the efficient frontier is solved - what will be the type of DEA model for this paper, see Tab. 1.

Territorial background of analysis is applied at 36 NUTS 2 region level within the EU Member States where geographic models have axis (see Table 2), as was mentioned in paper one; NUTS 2 regions are specified in Tab. 2. 


\section{URBANIZATION AND DYNAMICS OF ECONOMIC GROWTH}

Table 1. RTS Estimation to EU NUTS 2 Regions and Models Specification

(Sources: Annoni \& Kozovska, 2010, Annoni \& Dijkstra, 2013, Annoni et al., 2017, Hospers, 2003); own elaboration, 2019)

\begin{tabular}{|c|c|c|c|}
\hline $\begin{array}{c}\text { Geographic } \\
\text { Model }\end{array}$ & NUTS 2 & RTS & DEA Model \\
\hline Pentagon & $\begin{array}{c}\text { London-Paris } \\
\text { Axis }\end{array}$ & \multirow{5}{*}{ VRS } & \multirow{5}{*}{$\begin{array}{c}1^{\text {st }} \text { stage: SBMT VRS DEA Model of } \\
\text { Efficiency } \\
2^{\text {nd }} \text { stage: SBMT VRS DEA Model of } \\
\text { Super-Efficiency } \\
3^{\text {rd }} \text { stage: NUTS } 2 \text { classification }\end{array}$} \\
\hline Blue Banana & $\begin{array}{c}\text { London-Milan } \\
\text { Axis }\end{array}$ & & \\
\hline Sunbelt & $\begin{array}{c}\text { Milan-Valencia } \\
\text { Axis }\end{array}$ & & \\
\hline Yellow Banana & $\begin{array}{c}\text { Paris-Warsaw } \\
\text { Axis }\end{array}$ & & \\
\hline RCI & Merging Regions & & \\
\hline
\end{tabular}

DEA has become a popular method for its advantages: it can evaluate a DMU's performance with multiple inputs and multiple outputs (what fulfil the criteria of the dataset, i.e. many input and output factors of competitiveness based on the number of numerous initial indicators); it allows the units of input and output variables to be different (the criterion meet the paper outline, dataset represent various aspects of competitiveness on both side of input and output indicators); and it is not necessary to know the type of production function in advance.

However, DEA also has several limitations: the DMUs must be homogeneous (the criterion of homogeneity represent 36 EU NUTS 2 regions); to obtain the best results, the number of DMUs must be at least twice than the total number of input and output variables (the criterion is met as follows). If a performance measure is added or deleted from consideration, it will influence the relative efficiencies. Empirically, when the number of performance measures is high in comparison with the number of DMUs, then most of the DMUs are evaluated efficiently. Hence, the obtained results are not reliable. Suppose there are $n$ DMUs which consume $m$ inputs to produce $s$ outputs. There is a rough rule of thumb (Cooper et al., 2007) which expresses the relation between the number of DMUs and the number of performance measures. Toloo (2012) checked more than 40 papers that contain practical applications and statistically, they found out that in nearly all of the cases the number of inputs and outputs do not exceed 6. A simple calculation shows that when $m \leq 6$ and $s \leq 6$, then $3(m+s) \geq m \times s$. As a result, in this paper following formula (1) is applied:

$$
n \geq 3(m+s)
$$

In the paper, the rule of thumb is for the EU NUTS 2 regions and inputs and outputs met: $36 \geq 3(7+4), 36 \geq 3(11), 36 \geq 33$.

For calculations of EU NUTS 2 regions efficiency across core economic axis, SBMT not-focusing on input and output assuming VRS is used (2) (Tone, 2002):

$$
\min \rho=\frac{1-\frac{1}{m} \sum_{i=1}^{m}\left(s_{i}^{-} / x_{i q}\right)}{1+\frac{1}{r} \sum_{k=1}^{r}\left(s_{k}^{+} / y_{k q}\right)},
$$


subject to

$$
\begin{gathered}
\sum_{j=1}^{n} x_{i j} \lambda_{j}+s_{i}^{-}=x_{i q}, \\
\sum_{j=1}^{n} y_{k j} \lambda_{j}-s_{k}^{+}=y_{k q}, \\
\lambda_{j}, s_{k}^{+}, s_{i}^{-} \geq 0, \\
j=1,2, \ldots, n, j \neq q ; k=1,2, \ldots, r ; i=1,2, \ldots, m,
\end{gathered}
$$

where

$x_{i j}$ is the value of $i$-th input unit $U_{j}$;

$y_{k j}$ is the value of $k$-th output unit $U_{j}$;

$x_{i q}$ is the value of $k$-th input unit $U_{q}$;

$y_{k q}$ is the value of $k$-th output unit $U_{q}$.

Additional variables $s_{k}{ }^{+}$and $\mathrm{si}^{-}$measure the distance of inputs and outputs of virtual unit $\mathbf{X} \boldsymbol{\lambda}$ and $\mathbf{Y} \boldsymbol{\lambda}$ from inputs and outputs of evaluated unit $U_{q}$.

Expression in the numerator, resp. the denominator of the objective function (2) measures the average distance of inputs, resp. outputs from the efficient frontier. For efficient units, the value of the aim function equals to one, units with the value of the aim function less than one are inefficient. For VRS applies the condition of convexity $\mathbf{e}^{\mathbf{T}} \boldsymbol{\lambda}=\mathbf{1}$.

For the possibilityof efficient units' classification, SBMT Model of Super-Efficiency not-focusing on input and output assuming VRS isused (Tone, 2002).

In this model, evaluated unit $U_{q}$ is removedfrom the set of unitsandis searchedvirtualunit $U^{*}$ with inputs $x^{*}$ with inputsand outputs $y^{*}$, which will be efficient afterthisremoval. Inputsand outputs of unit $U^{*}$ will not be better in comparisonwith unit $U_{q}$. Value of Super-Efficiencyis definedas the distance ofinputs and outputs from both units $U_{q}$ and $U^{*}$. Ameasure of distance, metric $\delta$ is used, as follows (3):

$$
\min \delta=\frac{\frac{1}{m} \sum_{i=1}^{m}\left(x_{i}^{*} / x_{i q}\right)}{\frac{1}{r} \sum_{k=1}^{r}\left(y_{k}^{*} / y_{k q}\right)},
$$

subject to

$$
\begin{gathered}
\sum_{j=1}^{n} x_{i j} \lambda_{j}+s_{i}^{-}=x_{i}^{*}, \\
\sum_{j=1}^{n} y_{k j} \lambda_{j}-s_{k}^{+}=y_{k}^{*}, \\
x_{i}^{*} \geq x_{i q}, \\
y_{k}^{*} \leq y_{k q}, \\
\lambda_{q}=0, \\
\lambda_{j}, s_{k}^{+}, s_{i}^{-} \geq 0, \\
j=1,2, \ldots, n, j \neq q ; k=1,2, \ldots, r ; i=1,2, \ldots, m,
\end{gathered}
$$

where all symbols have the same interpretation as (2). 


\section{URBANIZATION AND DYNAMICS OF ECONOMIC GROWTH}

The numerator in the metric $\delta$ can be interpreted as the average rate of input increase of units $U^{*}$ compared with inputs of unit $U_{q}$.

For the optimal value of the objective function holds $\delta^{*} \geq 1$.

For inefficient units $\delta^{*}=1$, for efficient units $\delta^{*}>1$ and the higher value corresponds to the higher value of Super-Efficiency.

For VRS applies the condition of convexity $\mathbf{e}^{\mathbf{T}} \boldsymbol{\lambda}=\mathbf{1}$.

\section{Results of regional efficiency: case of the EU geographic models}

Analysis of regional competitiveness is based on selected indicators important for regional competitiveness based on the RCI approach. RCI presents the first measure of the level of competitiveness at the NUTS 2 regional level covering all of the EU28 countries. It takes into account both social and economic aspects, including the factors which describe the short and long-term potential of the economy.

RCI provides a synthetic picture of the level of the EU28 NUTS 2 regions representing, at the same time, a well-balanced plurality of different fundamental aspects. Final RCI shows a heterogeneous situation across the EU28 NUTS 2 regions with Eastern and Southern European regions showing lower performance while more competitive and resilient regions are observed in Northern Europe and parts of Continental Europe.

RCI shows a more polycentric pattern with substantial capital and metropolitan regions in many parts of Europe. Some capital regions are surrounded by similarly competitive regions, indicating the presence of spill over effects, but in many countries, the regions neighbouring the capital are far less competitive. In many countries, the capital region is far more competitive than the other regions in the same country and many countries have highly heterogeneous RCI scores.

A key question for the future is whether the strong performance of these capital and metropolitan regions will help to increase the performance of neighbouring regions or whether the gap between them and the other regions will widen. These results demonstrate that competitiveness in the EU has a strong regional dimension. The gap and variation in regional results should stimulate a debate to what extent these gaps are harmful to their national competitiveness and resilience of the economy as a whole, and to what extent the internal variation can be remediated.

The results point to the conclusion that economic activity is drawn into competitive locations, whereas these latter tend to cluster in delimited areas. Such a pattern is visible in the EU, where is possible to find regional zones including the core, periphery and the intermediary regions.

Using SBMT VRS model of efficiency and SBMT VRS model of Super-Efficiency is a measured level of efficiency in NUTS 2 regions represent the EU strength economic axis including Pentagon, Blue Banana, Sunbelt, and Yellow Banana and RCI2013/2016 merging regions. Based on the results of the SBMT VRS model of efficiency, evaluated the EU NUTS 2 regions are divided into two groups - efficient and inefficient regions (see Table 2). The Coefficient of Efficiency (CE) equals to one for efficient the EU NUTS 2 regions and is less than one for inefficient ones (the lower CE, the less inefficient unit).

The total number of evaluated the EU NUTS 2 regions is $36-29$ units were identified as efficient and 7 as inefficient, but what are the differences among them? Efficient the EU NUTS 2 regions are those on the main core economic axis according to RCI2013/2016 and in 
line with Pentagon and Blue Banana too. Less efficient, resp. inefficient the EU NUTS 2 regions are outside the main axis - these units are (in most cases) part of Yellow Banana and Sunbelt. Based on the gained results, we can confirm the initial assumption that Blue Banana and surrounding Pentagon/RCI2013/2016 areas may have the best starting position to grow in the next decades.

This fact is due to its diversified structure of the Blue Banana area (created by Pentagon areas and RCI2013/2016 merged regions too) rather than the Sunbelt and the Yellow Banana. Localised European policy of "regional realism" ultimately may thus help the most in bringing about a less unbalanced growth of Europe's geo-economy. In many ways, the EU situation prompts countries to seek alternative economic, political and security arrangements, particularly by looking to form and develop regional groupings.

The main questions of efficiency analysis were the following: How powerful in economic growth and efficient in competitiveness are the main core areas (Pentagon, Blue Banana, Sunbelt, Yellow Banana, and RCI2013)? Which the EU NUTS 2 regions are the most crucial for the European economy? Will be DEA classification of the EU NUTS 2 regions in line with the importance of areas based on the theory of geographic models? For their answering SBMT VRS model of Super-Efficiency was used and the final ranking was ordered based on the Coefficient of Super-Efficiency (CSE) (see Tab. 2).

Evaluated the EU NUTS 2 regions are based on CSE classified from the most to the least efficient.

The category of the EU most efficient NUTS 2 regions $\left(1^{\text {st }}-14^{\text {th }}\right.$ positions: CSE is greater than 2.000, resp. in one case greater than 3.000, specifically NUTS 2 region UKI1) contains large and wealthy urban conglomerations with high shares of employment in the service sector. These areas have a diversified economic and institutional structure and advanced educational and infrastructure facilities. Compared with these contemporary growth poles, intermediate efficient NUTS 2 regions $\left(15^{\text {th }}-29^{\text {th }}\right.$ positions: CSE is greater than 1.000) are less dynamic: they often have to cope with adaptation problems. Overspecialisation in manufacturing together with a rigid institutional structure have created lock-in situations that hamper the restructuring towards a service economy, what could also be the case of inefficient NUTS 2 regions $\left(30^{\text {th }}-36^{\text {th }}\right.$ positions: CE is less than 1.000$)$, they have experienced no significant difficulties in making the switch-over to an industrial or services economy.

This classification of geo-economic areas makes clear that the pattern of economic activity in Europe is unevenly distributed. Results of efficiency analysis show a more polycentric pattern with strong capital and metropolitan regions in many parts of Europe. Similarly, competitive regions surround some capital regions, but in many countries, regions neighbouring the capital are less competitive.

Despite the increasing level of mobility of economic sources, i.e. inputs to find out the better condition for economic activities, access to places, and services are still difficult, what has an impact on economic development of regional areas distant from the leading economic centres of the country, especially major cities and their surrounding areas. Efficiency results underline that competitiveness has a strong regional dimension, which national level analysis does not capture (Annoni \& Dijkstra, 2013, Annoni et al., 2017).

Fig. 3 shows the development of efficiency level for evaluated NUTS 2 regions based on SBMT VRS model of efficiency. One horizontal axis on the value 1.000 represents the boundary between efficiency and inefficiency - within our sample is in the case of the EU 


\section{URBANIZATION AND DYNAMICS OF ECONOMIC GROWTH}

NUTS 2 region, DE60 Hamburg. Six vertical axes imagine breaking points for substantial decrease among efficiency levels of evaluated regions.

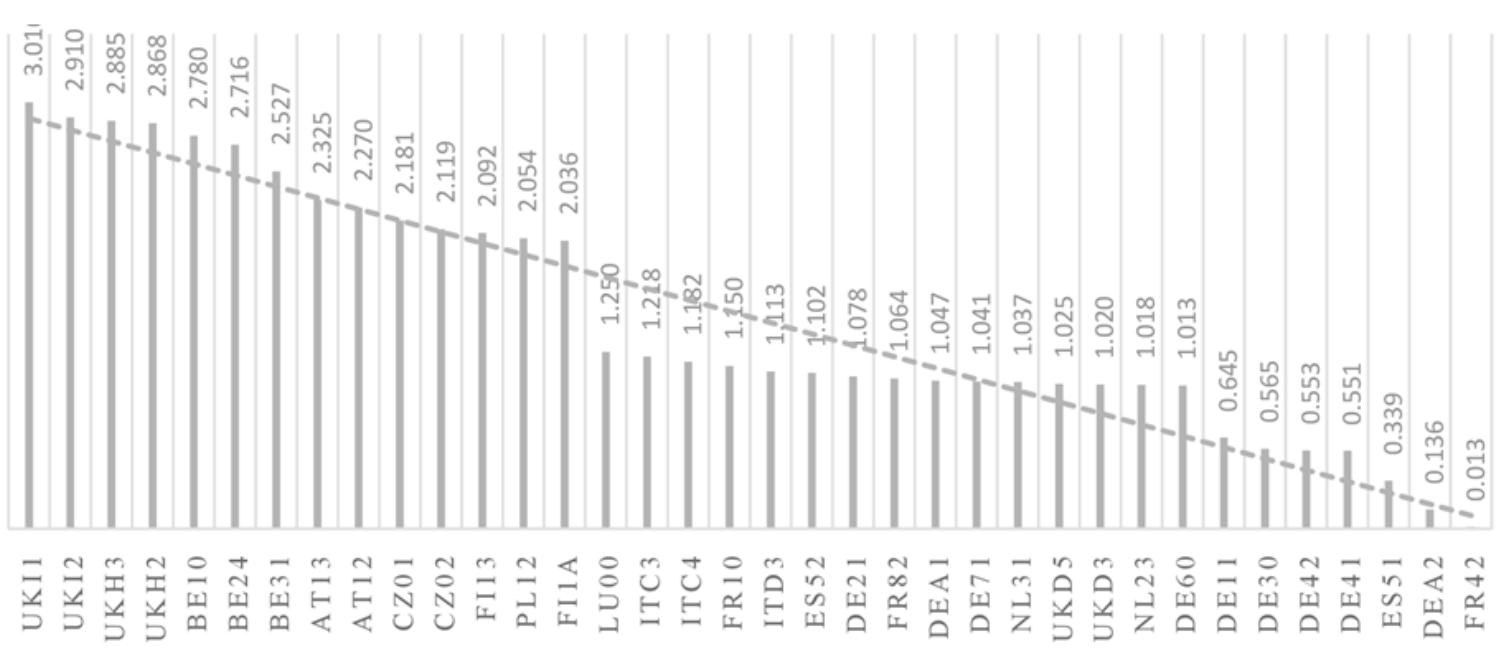

Figure 3 - Development of Efficiency Level for Evaluated NUTS 2 Regions

(own calculation and elaboration, 2019)

For each unit identified as inefficient, DEA creates a group of so-called Peer-Units which suggest a strategy for the optimal combination of inputs and outputs to enhancing their efficiency. For this strategy, efficient units are used as a benchmark because these units move on the efficient frontier and thus their combination of inputs and outputs seems to be optimal - no need to change. In Table 3 is possible to see inefficient NUTS 2 regions and for each of them the benchmark NUTS 2 regions which are efficient and seems to be the convenient background for calculation of changes in values for original inputs and outputs - optimal strategy how to improve efficiency.

\section{Conclusion}

A casual look at the geographical map of any territory reveals an uneven distribution of population across space. These maps often feature small 'nodal' points of high population density, as opposed to the less inhabited surrounding. Indeed, the uneven distribution of population and economic activity across space can be somewhat attributed to natural causes. Certain climatic conditions and terrain configuration render chunks of territory uninhabitable. On the other hand, fertile land along water sources provides favourable conditions for growth and development of settlements.

However, much of the pattern of the uneven spatial distribution of economic activity cannot be attributed solely to geographical reasons, but to a range of endogenous factors (De Bruyne, 2006). 
Table 2 - Efficiency and Super-Efficiency SBMT Results for NUTS 2 Regions (own calculation and elaboration, 2019)

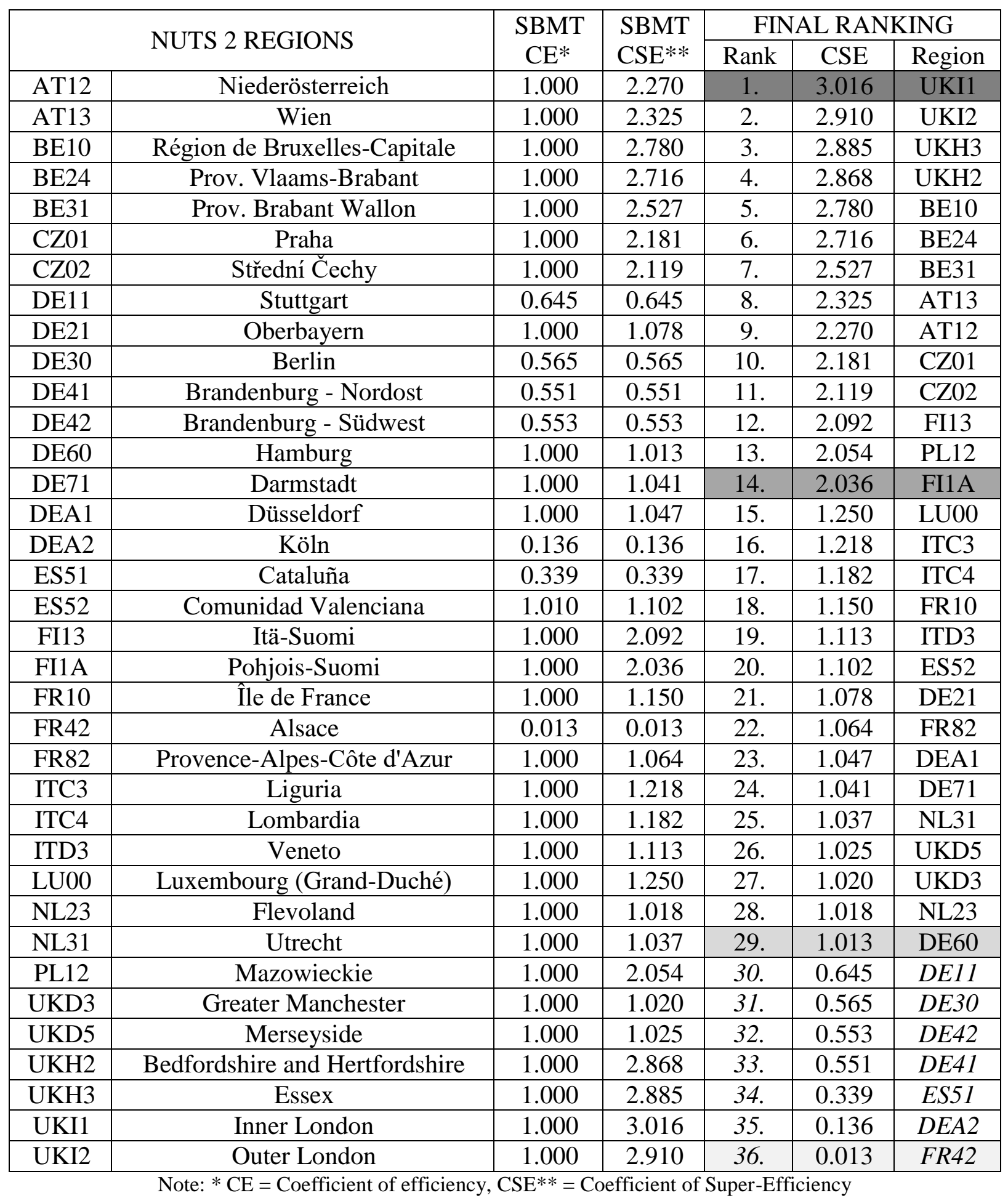




\section{URBANIZATION AND DYNAMICS OF ECONOMIC GROWTH}

Table 3.Optimal Peer-Units for Improving Inefficient NUTS 2 Regions (own calculation and elaboration, 2019)

\begin{tabular}{|c|c|c|c|}
\hline \multicolumn{2}{|c|}{ Inefficient NUTS 2 Region } & \multicolumn{2}{|c|}{$\begin{array}{c}\text { Benchmark NUTS } 2 \text { Regions to Change Level of } \\
\text { Inputs and Outputs }\end{array}$} \\
\hline DE11 & Stuttgart & $\begin{array}{l}\text { FR10 } \\
\text { ITC4 }\end{array}$ & $\begin{array}{l}\text { Île de France } \\
\text { Lombardia }\end{array}$ \\
\hline DE30 & Berlin & $\begin{array}{l}\text { ITC3 } \\
\text { ITC4 } \\
\text { PL12 } \\
\end{array}$ & $\begin{array}{l}\text { Liguria } \\
\text { Lombardia } \\
\text { Mazowieckie }\end{array}$ \\
\hline DE41 & Brandenburg - Nordost & $\begin{array}{l}\text { ITC3 } \\
\text { ITC4 } \\
\text { PL12 } \\
\end{array}$ & $\begin{array}{l}\text { Liguria } \\
\text { Lombardia } \\
\text { Mazowieckie }\end{array}$ \\
\hline DE42 & Brandenburg - Südwest & $\begin{array}{l}\text { ITC3 } \\
\text { ITC4 } \\
\text { PL12 }\end{array}$ & $\begin{array}{l}\text { Liguria } \\
\text { Lombardia } \\
\text { Mazowieckie }\end{array}$ \\
\hline DEA2 & Köln & $\begin{array}{l}\text { DEA1 } \\
\text { FR10 } \\
\text { ITC4 } \\
\text { PL12 }\end{array}$ & $\begin{array}{l}\text { Düsseldorf } \\
\text { Île de France } \\
\text { Lombardia } \\
\text { Mazowieckie }\end{array}$ \\
\hline ES51 & Cataluña & $\begin{array}{l}\text { ITD3 } \\
\text { PL12 }\end{array}$ & $\begin{array}{l}\text { Veneto } \\
\text { Mazowieckie }\end{array}$ \\
\hline FR42 & Alsace & $\begin{array}{l}\text { FR10 } \\
\text { ITC4 } \\
\text { PL12 } \\
\end{array}$ & $\begin{array}{l}\text { Île de France } \\
\text { Lombardia } \\
\text { Mazowieckie }\end{array}$ \\
\hline
\end{tabular}

In this context, it is the socio-institutional framework which becomes the determinant of the attractiveness of territory for inflows of economic activity. As stated Danon (2014), given that the activity is unevenly distributed in the function of several endogenous factors, across a set of different territories, these inter-regional differences can induce migrations of footloose factors of production between locations. In this context, as long as we assume a finite set of factors of production with a marginal level of mobility; territories can be considered to be competing for attraction and retention of economic activity. Following this logic, then, a degree of successfulness in this competition can be called territorial competitiveness (Camagni, 2002).

Thus a competitive region, experiencing the prevalence of agglomerative over dispersive forces, enjoys constant net positive migration of mobile factors of production. On the other end of the scale, an uncompetitive region faces constant danger of desertification of footloose factors the regional focus reflects the increasing consensus that they are the primary spatial units where growing returns to scale are created, while knowledge is generated and circulated, all resulting in creation of agglomerations of economic activity (Huggins, 2003). In this context, it is affirmed the position that it is areas - sub-national territories - rather than nation-states, which compete.

A region is a useful choice principally because it is more or less homogeneous, with a relatively similar institutional framework, economic and social structure within its territory, while it usually doesn't dispose of nation-state prerogatives. Therefore, the territory has only 
recently become a terrain of strenuous economic research. With the New Economic Geography integrating into the mainstream, many spatial subjects, including territorial, or regional, competitiveness are being increasingly inquired. However, this branch of economic geography is relatively underdeveloped, while it even lacks a universally accepted definition and metrics. Over the last decades, regional competitiveness has been intensely investigated (Staníčková, 2018).

This paper presented a framework for defining regional competitiveness and specifying quantitative measures of competitiveness that can serve as foci for the comprehensive characterisation of the socio-economic problem to establish needs and priorities. Regional competitiveness is a much broader concept beyond the economic dimension. An efficient economic integration arrangement should generate higher total welfare than any other arrangement.

It's possible to expect that the EU core economic axis such as Pentagon, Blue Banana, Sunbelt, Yellow Banana and RCI2013/2016 merging regions will also be the European growth axis in the next decades. This is not to say that there are no chances for other NUTS 2 regions in the European economy.

As Hospers (2003) also introduced, in addition to Blue Banana new growth poles might emerge in Europe. The prospects of new areas depend upon their capacity to solve transition problems and to make use of the rising demand for services. From this perspective, Sunbelt may indeed have growth potential.

The pleasant climate and attractive environment of this area along the Mediterranean coast offer opportunities to expand tourist, cultural and leisure services. Like peripheral agricultural areas in the Mediterranean, most regions in Central and Eastern Europe still have to cope with economic and institutional inertia effects resulting from the past.

Therefore, these inefficient areas will be the objects of the next research. Via construction the Peer-Units, a strategy of optimal settings of inputs and outputs will be suggested for enhancing their efficient options and economic positions within the EU axis.

\section{References:}

Alexiadis, S. (2013). Convergence Clubs and Spatial Externalities. Models and Applications of Regional Convergence in Europe. Berlin: Springer.

Annoni, P. \& Dijkstra, L. (2013). EU Regional Competitiveness Index 2013. Luxembourg: Publication Office of the European Union.

Annoni, P. \& Kozovska, K. (2010). EU Regional Competitiveness Index 2010. Luxembourg: Publication Office of the European Union.

Annoni, P., Dijkstra, L. \& Gargano, N. (2017). EU regional competitiveness Index 2016. Working Paper WP 02/2017. Brussel: Directorate-General for Regional and Urban Policy.

Banker, R.D., Charnes, A. \& Cooper, W.W. (1984). Some models for estimating technical and scale inefficiencies in data envelopment analysis. Management Science, 30(9), 1078-1092.

Camagni, R. (2002). On the concept of territorial competitiveness: Sound or misleading? Urban Studies, 39(13), 2395-2411.

Charnes, A., Cooper, W.W. \& Rhodes, E. (1978). Measuring the efficiency of decision making units. European Journal of Operational Research, 2 (6), 429-444.

Corrado, L., Martin, R. \& Weeks, M. (2005). Identifying and Interpreting Regional Convergence Clusters across Europe. The Economic Journal, 115(502), 133-160.

Danon, M. (2014). Constructing a Novel Competitiveness Index for European Regions. GREDEG Working Papers 2014-42. Nice: University of Nice Sophia Antipolis. 


\section{URBANIZATION AND DYNAMICS OF ECONOMIC GROWTH}

De Bruyne, K. (2006). The location of economic activity. First versus second nature core-periphery theories. Review of Business and Economics, 51(1), 75-104.

Durlauf, S., Johnson, P. \& Temple, J.R.W. (2005). Growth Econometrics. In Aghion, P.\& Durlauf, S. (eds.). Handbook of Economic Growth (555-677). North Holland: Elsevier.

Farrell, M.J. (1957). The Measurement of Productive Efficiency. Journal of the Royal Statistical Society. Series A (General), 120(3), 253-290.

Fischer, M.M. \& Stirböck, C.(2006). Pan-European regional income growth and club-convergence. Insights from a spatial econometric perspective. The Annals of Regional Science, 40(4), 693721.

Hospers, G. J. (2003). Beyond the Blue Banana? Structural Change in Europe's Geo-Economy. Intereconomics, 38(2), 76-85.

Huggins, R. (2003). Creating a UK competitiveness index: Regional and local benchmarking. Regional Studies, 37(1), 89-96.

Mihaiu, D. M., Opreana, A. \& Cristescu, M. P. (2010). Efficiency, effectiveness and performance of the public sector. Romanian Journal of Economic Forecasting, 4(1), 132-147.

Nevima, J. \& Ramík, J. (2010). Application of DEA for evaluation of regional efficiency of EU regions. In $28^{\text {th }}$ International Conference on Mathematical Methods in Economics 2010. České Budějovice: University of South Bohemia.

Pakšiová, R. (2017). The Critical analysis of profit for its allocation decision-making. In Decision making for small and medium-sized enterprises. Scientific Annals of Economics and Business, 64(SI), 41-56.

Poledníková, E. (2014). Comparison of Regions' Ranking by MCDM methods: the Case of Visegrad Countries. Scientific Journal WSEAS Transactions on Business and Economics, 11(1), 507518.

Porter, M. E. (2003). The Economic Performance of Regions. Regional Studies, 37(6/7), 549-578.

Staníčková, M., (2018). EU Competitiveness and Resilience: Evidence-based on Regional Level. SAEI, 51. Ostrava: VSB-TU Ostrava.

Staníčková, M. \& Melecký, L. (2018). Boosting the EU Competitiveness as Response to Economic Shocks: Composite Weighted Index of Regional Resilience. In Ushakov, D. (ed.). Economic Reforms for Global Competitiveness (209-228). Hershey PA: IGI Global.

Paper submitted

Paper accepted for publishing

Paper published online
07 July 2019

26 September 2019

30 November 2019 